\title{
CLINICAL AND CYTOMORPHOLOGICAL EVALUATION OF PRIMARY LUNG NEOPLASMS IN A TERTIARY CARE TEACHING CENTRE OF SOUTH INDIA
}

\author{
Priya Poickattusseril Vasu¹, Deepa Sujatha², Jayalakshmy Payippat Leelamma ${ }^{3}$ \\ ${ }^{1}$ Associate Professor (CAP), Department of Pathology, Government Medical College, Kottayam. \\ ${ }^{2}$ Assistant Professor, Department of Pathology, Government Medical College, Kottayam. \\ ${ }^{3}$ Assistant Professor, Department of Pathology, Government Medical College, Kottayam.
}

\section{ABSTRACT}

\section{BACKGROUND}

Lung cancer is the leading cause of cancer mortality in the world. Two-thirds of patients present in advanced stages and tissue diagnosis is usually based on cytology or small biopsy specimens, which has a direct impact on patient management and prognosis. Several epidemiological studies have showed that since 1960s there is a change in pattern of lung cancer.

Aim: To evaluate clinical profiles and cytomorphological features of lung cancer cases diagnosed in our institution.

\section{MATERIALS AND METHODS}

This one year retrospective study was approved by Scientific Review Committee and Institutional Review Board. Clinical and demographic data were collected from medical records and cytomorphological patterns were evaluated by reviewing the cytology smears retrieved from the archives in our centre.

\section{RESULTS}

Clinico-pathological analysis of 100 cases of primary lung malignancies showed peak incidence in $7^{\text {th }}$ decade (39\%) with male predominance (95\%). Cough was the most frequent symptom (53\%), right lung was the commonest site (66\%) and located centrally (44\%). Associated pleural effusion, past history of pulmonary tuberculosis and family history of malignancy were observed 19\%, 9\% and 5\% cases, respectively. Predominant tumour types were adenocarcinoma (40\%), squamous cell carcinoma (17\%) and small cell carcinoma (12\%); 72\% cases had disease above TNM stage II.

\section{CONCLUSION}

In many situations cytology is the only diagnostic method available for guiding therapeutic decisions in the management of patients with lung cancer. Similar to the change in pattern of primary lung carcinoma in Western countries, adenocarcinoma of lung has surpassed squamous cell carcinoma here too.

\section{KEYWORDS}

Lung Cancer, Cytology, Small Cell Lung Carcinoma, Non-Small Cell Carcinoma, Adenoid Cystic Carcinoma Lung.

HOW TO CITE THIS ARTICLE: Vasu PP, Sujatha D, Leelamma JP. Clinical and cytomorphological evaluation of primary lung neoplasms in a tertiary care teaching centre of south India. J. Evolution Med. Dent. Sci. 2017;6(41):3240-3245, DOI: 10.14260/Jemds/2017/702

\section{BACKGROUND}

Global cancer burden raised to 14.1 million new cases in 2012 compared with 12.7 million in 2008. About 8.2 million cancer-related deaths occurred in 2012, compared to 7.6 million in 2008. Lung cancer is the most commonly diagnosed cancer worldwide, accounting for $13 \%$ ( $n=1.8$ million) of the total. It is the commonest cause of cancer mortality in the world, constituting $19.4 \%$ ( $n=1.6$ million) of the total.[1] The incidence and death rate of lung cancer varies with geographic region, environmental factors and ethnicity. In the United States, the age adjusted death rate of lung cancer per 100,000 populations was 35.04 in 2014, whereas in India it was 1.38.[2] In 2013, there was an estimated 415,707 people living with lung and bronchus cancer in the United States.[3]

Financial or Other, Competing Interest: None.

Submission 10-04-2017, Peer Review 09-05-2017,

Acceptance 15-05-2017, Published 22-05-2017.

Corresponding Author:

Dr. Deepa $S$,

Assistant Professor,

Department of Pathology,

Govt. Medical College,

Kottayam-686008, Kerala.

E-mail:drdeeps@gmail.com

DOI: $10.14260 /$ jemds $/ 2017 / 702$
In India, increased rate of diagnosis of lung carcinoma was first reported by Viswanathan et al in early 1960s. ${ }^{4]}$

According to the first population based cancer registry from Eastern part of India published in 2002, the highest number of lung cancer cases among males has been documented from Kolkata and its suburbs compared to other parts of India.[5]

In the United States, lung and bronchus cancer is most frequently diagnosed among people aged 65 to 74, median age at diagnosis being 70.[3] Symptomatic lung cancers are usually advanced cancers; and patients presenting with progressive dyspnoea, cough, haemoptysis, hoarseness of voice, chest pain and loss of weight or no symptoms at all. Lung cancer can occur anywhere in the lungs, but more common in the periphery of the lungs than in the hilar region, and more common in the upper lobe than in other lobes. At the time of diagnosis, only $16 \%$ of the patients have disease confined to the primary site, $23 \%$ have regional lymph node involvement and more than $60 \%$ have evidence of distant metastatic disease usually to liver, bone, brain, adrenal gland or lungs. Computed Tomography (CT) of chest is more informative than chest radiography in terms of tumour size, shape and location as well as in terms of staging.[6] Endocrine and paraneoplastic syndromes are common in lung cancer. ${ }^{[7]}$ 
Previously, for therapeutic decisions lung cancer was categorised as small cell carcinoma or Non-Small Cell Lung Carcinoma (NSCLC) and the major histologic classes of NSCLC described were adenocarcinoma, squamous cell carcinoma, large cell carcinoma and other less common tumour subtypes. ${ }^{[8]}$ However, histologic heterogeneity is common in lung cancers with variation in appearance and differentiation from microscopic field to field. [9] One of the greatest advances in the past decade in lung cancer management is the concept of "personalised medicine." Currently, precise subtyping of NSCLC into adenocarcinoma and squamous cell carcinoma has a direct impact on patient management as well as prognosis. Two-thirds of patients are presenting in advanced stages, and their diagnosis is usually established based on cytology or small biopsy specimens.[10] The relevant cytological features of small cell carcinoma are nuclear moulding, small cell size and scanty basophilic cytoplasm.[11,12] Neoplasms with patterns of acinar, papillary, lepidic or micropapillary are diagnostic of adenocarcinoma. Unequivocal keratinisation, well-formed classical bridges and tadpole cells are helpful for the diagnosis of squamous cell carcinoma. Neoplasms that lack any of these specific morphologic patterns are designated as Non-Small Cell Carcinoma Not Otherwise Specified (NSCC NOS).[10]

Epidemiological studies have showed that since 1960s in the Western countries and many Asian countries, adenocarcinoma of lung has surpassed squamous cell carcinoma.[13-15] In India, studies conducted in different parts of the country have projected varying observations in this aspect.[16-22] The main objective of this descriptive study is to evaluate the clinical profiles and cytomorphological features of lung cancer cases, which were diagnosed in our institution during the year 2015 .

\section{MATERIALS AND METHODS}

This is a retrospective study approved by Scientific Review Committee and Institutional Review Board and conducted in a tertiary care teaching centre in central Kerala. All cases of clinically suspected primary lung neoplasm, which were diagnosed in the cytology division of Department of Pathology, over a period of 12 months from January 2015 to December 2015 were included in this study. Clinical and demographic information of all cases were collected from medical records available in our centre. Data collected include patient's age, sex, symptoms, relevant past illness, family history, radiological findings and TNM stage at the time of diagnosis. The cytomorphological patterns of all these cases were evaluated by reviewing the Papanicolaou and/or May-Grunwald Giemsa stained cytology smears retrieved from the archives in our centre and were subtyped based on 2015 WHO Classification of lung tumours. All the clinical and cytomorphological data were analysed by SPSS package 16.0.

\section{RESULTS}

In our centre during the study period, a total of 108 cases of primary lung malignancies were diagnosed based on the cytological examination, but due to incomplete clinical information 8 cases were excluded from this study.

Clinico-pathological analysis was done in a total of 100 cases of primary lung malignancies diagnosed in our centre during the study period. The age of patients varied from 25 to 86 years and the mean age was $62.5(62.5 \pm 9.3)$ years; 95 cases were males with male-to-female ratio of 19:1. In the study group the common clinical presentations were cough (53), dyspnoea (37), chest pain (26), haemoptysis (20), hoarseness of voice (15), vertigo (2) and multiple skin nodules (1). In 38 cases, both loss of weight and appetite were present. Features of obstruction to Superior Vena Cava (SVO) and Horner's syndrome were observed in 3 and 1 case respectively; 9 patients had history of treatment for pulmonary tuberculosis and 5 had family history of cancer. Two cases had polyclonal gammopathy and one had leukoerythroblastic blood picture.

CT of chest showed right lung as the site of primary lesion in $66 \%(n=66)$ of patients. Location of primary tumour was central (hilar or perihilar) in 44 cases, peripheral in 35 cases, apical in 3 cases and basal in 2 cases. Extensive lesions in lung with both central and peripheral involvement were present in 16 cases. At the time of diagnosis, pleural effusion $(19 \%$ cases), pericardial effusion ( $1 \%$ case), direct tumour invasion into chest wall (20\% cases), left atrium ( $1 \%$ case) and distant metastasis (38\% cases) were detected in CT. Malignant cells could be demonstrated in pleural fluid in 3 out of 19 cases with pleural effusion.

Cytology showed little anisocytosis in 27 cases, while marked anisocytosis with many pleomorphic tumour cells and multinucleated giant cells were seen in 9 and 8 cases respectively. Cells had scanty cytoplasm in 17 cases and ample amount of cytoplasm in 47 cases. Cytoplasmic vacuolation in a few cells was present in 13 cases, while 1 case had an exclusive population of vacuolated cells with eccentrically placed nucleus. In 39 cases nucleus was central, while a mixed population was observed in 60 cases. Marked nuclear molding was observed in 8 cases. Chromatin was finely granular in 12 cases, coarsely clumped in 22 cases, vesicular in 19 cases and showed mixed features in 47 cases. In 44 cases cells showed nucleolus, of which 13 had micronucleolus, 27 had macronucleolus and 4 had mixed features.

Cases with uniform small round or oval cells having scanty cytoplasm; nuclear molding and finely granular chromatin were diagnosed as small cell lung carcinoma, which accounted for 12 cases. Squamous differentiation was observed in 17 cases such as keratinisation (9), tadpole cells (13) and intercellular bridging (5). Clear glandular pattern was observed in some cases such as acinar (19), papillary (6) and papillaroid (1). However, considering the cohesive nature of tumour cells, amount and vacuolation of cytoplasm, location of nucleus, chromatin pattern and type of nucleolus, a total of 40 cases were diagnosed as adenocarcinoma; 1 case had small round cells in microacinar pattern, scanty cytoplasm and pink globules in background, which was diagnosed as adenoid cystic carcinoma. In 30 cases, no substantial neuroendocrine or squamous or glandular differentiation was observed.

Table 1. shows distribution of cytology specimens and cytology diagnosis; Table 2. shows distribution of important clinical profiles according to diagnosis. Table 3. shows age distribution of patients in the study group. 


\begin{tabular}{|c|c|c|c|c|c|c|c|}
\hline \multirow{2}{*}{ Specimen } & \multicolumn{9}{|c|}{ Diagnosis } & \multirow{2}{*}{ Total } \\
\cline { 2 - 8 } & SCLC & SCC & ADC & NSCC NOS & AdCC & PMC & 0 \\
\hline CTGFNA Lung & 4 & 5 & 22 & 13 & 0 & 0 & 0 \\
\hline FNA Lymph Node & 6 & 4 & 13 & 7 & 0 & 0 & 30 \\
\hline Imprint Cytology & 1 & 6 & 1 & 6 & 1 & 0 & 15 \\
\hline FNA of Bone Lesion & 1 & 1 & 1 & 3 & 0 & 0 & 6 \\
\hline BA Lavage & 0 & 1 & 1 & 0 & 0 & 1 & 3 \\
\hline Sputum Cytology & 0 & 0 & 1 & 0 & 0 & 0 & 1 \\
\hline Pleural Fluid & 0 & 0 & 1 & 0 & 0 & 0 & 1 \\
\hline Total & $\mathbf{1 2}$ & $\mathbf{1 7}$ & $\mathbf{4 0}$ & $\mathbf{2 9}$ & $\mathbf{1}$ & $\mathbf{1}$ & $\mathbf{1 0 0}$ \\
\hline
\end{tabular}

CTGFNA - CT-guided FNA, SCLC - Small Cell Lung Carcinoma, SCC- Squamous Cell Carcinoma, ADC- Adenocarcinoma, AdCC- Adenoid Cystic Carcinoma, NSCC NOS- Non-Small Cell Carcinoma Not Otherwise Specified,

PMC- Positive for Malignant Cells

Table 1. Distribution of Cytology Specimens and Diagnosis

\begin{tabular}{|c|c|c|c|c|c|c|c|}
\hline Diagnosis & SCLC & SCC & ADC & AdCC & NSCC NOS & PMC & Total \\
\hline Number & 12 & 17 & 40 & 1 & 29 & 1 & 100 \\
\hline M: F & $11: 1$ & $17: 0$ & $39: 1$ & $1: 0$ & $26: 3$ & $1: 0$ & $95: 5$ \\
\hline Right: Left & $6: 6$ & $11: 6$ & $27: 13$ & $1: 0$ & $21: 8$ & $0: 1$ & $66: 34$ \\
\hline C:P:A:B:E & $9: 0: 0: 0: 3$ & $9: 1: 0: 1: 6$ & $10: 24: 1: 0: 5$ & $1: 0: 0: 0: 0$ & $14: 10: 2: 1: 2$ & $1: 0: 0: 0: 0$ & $44: 35: 3: 2: 16$ \\
\hline PE & 1 & 5 & 9 & 0 & 4 & 0 & 19 \\
\hline CWI & 0 & 4 & 8 & 0 & 8 & 0 & 20 \\
\hline PTB & 2 & 1 & 2 & 0 & 4 & 0 & 9 \\
\hline CF & 1 & 0 & 3 & 0 & 0 & 1 & 5 \\
\hline $\begin{array}{c}\text { Primary } \\
\text { T1:T2:T3:T4 }\end{array}$ & $0: 7: 2: 3$ & $0: 6: 7: 4$ & $1: 28: 8: 3$ & $0: 0: 1: 0$ & $0: 18: 10: 1$ & $0: 0: 1: 0$ & $1: 59: 29: 11$ \\
\hline
\end{tabular}

M: F- Male: Female, Tumour Location C:P:A:B:E- Central: Peripheral: Apical: Basal: Extensive, PE- Pleural Effusion, CWI- Chest Wall Invasion, PTB- Pulmonary Tuberculosis, CF- Cancer in Family

Table 2. Distribution of Demographic and Clinical Profiles of Cases according to Diagnosis

\begin{tabular}{|c|c|c|c|c|c|c|c|c|}
\hline Age & $\begin{array}{c}\mathbf{3}^{\mathrm{RD}} \\
(\mathbf{2 1}-\mathbf{3 0} \mathbf{y})\end{array}$ & $\begin{array}{c}\mathbf{4}^{\mathrm{TH}} \\
\mathbf{( 3 1}-\mathbf{4 0} \mathbf{y})\end{array}$ & $\begin{array}{c}\mathbf{5}^{\mathrm{TH}} \\
\mathbf{( 4 1}-\mathbf{5 0} \mathbf{y})\end{array}$ & $\begin{array}{c}\mathbf{6}^{\mathrm{TH}} \\
(\mathbf{5 1}-\mathbf{6 0} \mathbf{y})\end{array}$ & $\begin{array}{c}\mathbf{7}^{\mathrm{TH}} \\
(\mathbf{6 1}-\mathbf{7 0} \mathbf{y})\end{array}$ & $\begin{array}{c}\mathbf{8}^{\mathrm{TH}} \\
(\mathbf{7 1}-\mathbf{8 0} \mathbf{y})\end{array}$ & $\begin{array}{c}\mathbf{9}^{\mathrm{TH}} \\
(\mathbf{8 1}-\mathbf{9 0} \mathbf{y})\end{array}$ & Total \\
\hline No: & 1 & 0 & 8 & 34 & 39 & 16 & 2 & 100 \\
\hline$\%$ & 1 & 0 & 8 & 34 & 39 & 16 & 2 & 100 \\
\hline \multicolumn{7}{|c|}{ Table 3. Age Distribution of Patients (in decade) in the Study Group } \\
\hline
\end{tabular}

\begin{tabular}{|c|c|c|c|c|}
\hline Study & $\begin{array}{c}\text { Sundaram } \\
\text { et al(8) } \\
(n=60) \\
\end{array}$ & $\begin{array}{c}\text { Dhandapani } \\
(21) \\
(\mathrm{n}=54) \\
\end{array}$ & $\begin{array}{c}\text { Binukumar } \\
\text { et al(22) } \\
(n=281)\end{array}$ & $\begin{array}{c}\text { Current } \\
\text { Study } \\
(n=100)\end{array}$ \\
\hline $\begin{array}{l}\text { Place and } \\
\text { Year }\end{array}$ & $\begin{array}{l}\text { Kolkata } \\
-2010\end{array}$ & $\begin{array}{c}\text { Chennai } \\
-2013\end{array}$ & \begin{tabular}{|c|} 
Kerala \\
-2010 \\
\end{tabular} & $\begin{array}{l}\text { Kerala } \\
-2015\end{array}$ \\
\hline $\begin{array}{l}\text { Peak Age } \\
\text { Group }\end{array}$ & $\begin{array}{l}61-70 \\
\text { Years }\end{array}$ & - & $\begin{array}{l}51-60 \\
\text { Years }\end{array}$ & $\begin{array}{l}61-70 \\
\text { Years }\end{array}$ \\
\hline Mean Age & 63 & 59.8 & - & 62.5 \\
\hline $\begin{array}{c}\text { Male: } \\
\text { Female }\end{array}$ & $3.2: 1$ & $3.9: 1$ & 6.0: 1 & $19: 1$ \\
\hline $\begin{array}{l}\text { Cancer in } \\
\text { Family }\end{array}$ & - & - & $21.7 \%$ & $5 \%$ \\
\hline $\begin{array}{c}\text { Chief } \\
\text { Complaint }\end{array}$ & - & $\begin{array}{l}\text { Cough } \\
(61.1 \%)\end{array}$ & - & $\begin{array}{l}\text { Cough } \\
(53 \%)\end{array}$ \\
\hline $\begin{array}{l}\text { Pleural } \\
\text { Effusion }\end{array}$ & - & $27.8 \%$ & - & $19 \%$ \\
\hline Right: Left & - & - & 0.9: 1 & $1.9: 1$ \\
\hline $\begin{array}{l}\text { SCLC: } \\
\text { NSCC }\end{array}$ & $1: 10$ & $1: 16.8$ & - & $1: 7.3$ \\
\hline $\begin{array}{l}\text { Dominant } \\
\text { NSCLC }\end{array}$ & $\mathrm{ADC}$ & $\mathrm{ADC}$ & SCC & $\mathrm{ADC}$ \\
\hline Stage IV & $60 \%$ & - & $50 \%$ & $38 \%$ \\
\hline \multicolumn{5}{|c|}{ Table 4. Comparison of Clinico- } \\
\hline
\end{tabular}

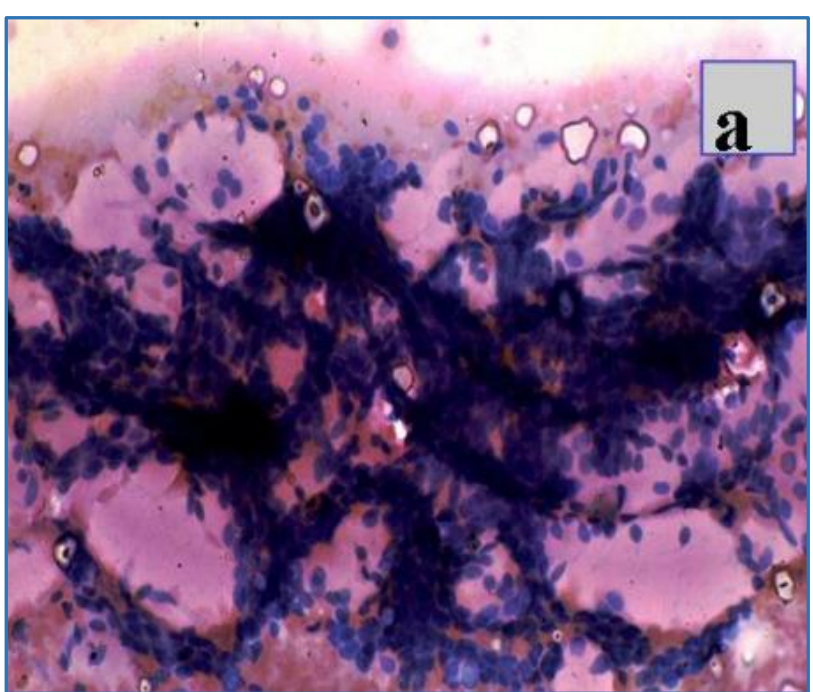

Figure 1a. Cytology Smear showing Cellular Material with Hyaline Spherical Globules of varying Size and adherent Tumour Cells (Pap stain, $x$ 100) 


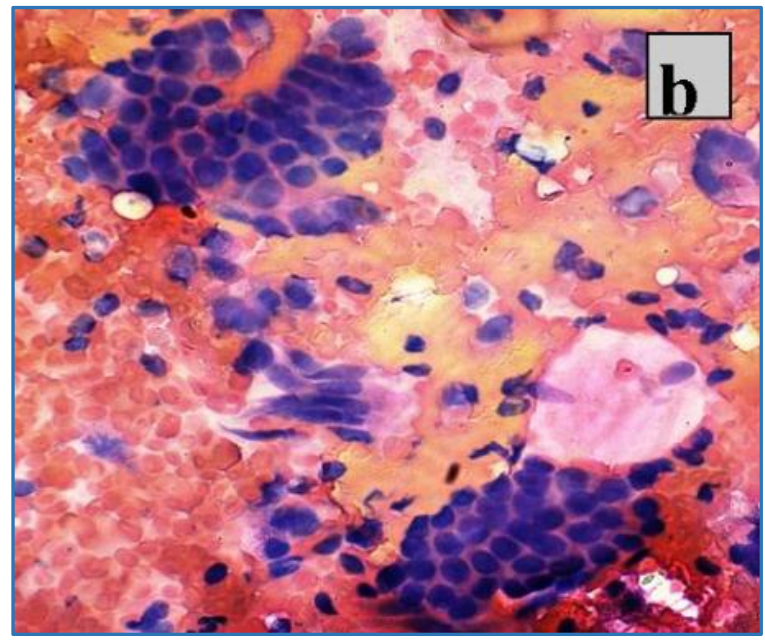

Figure 1b. Cytology Smear showing Small Sheets of relatively Uniform Small round-to-oval Cells with Scanty Cytoplasm, Round or Oval Nuclei and coarsely Granular Chromatin along with a Hyaline Spherical Globule and a few Bronchial Epithelial Cells (Pap stain, $x$ 400)

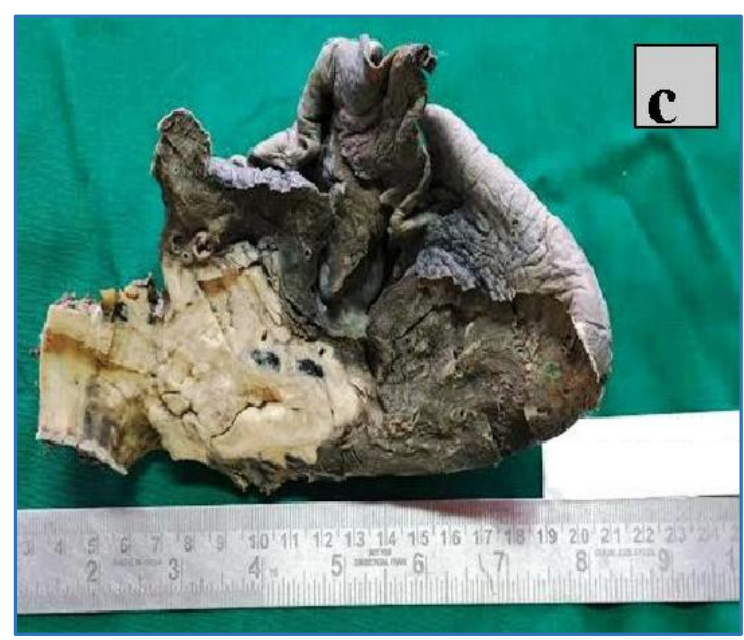

Figure 1c. Right Pneumonectomy Specimen showing Gray-White Lesion involving the Bronchus and Lung Parenchyma measuring $9 \times 7 \times 5 \mathrm{cms}$

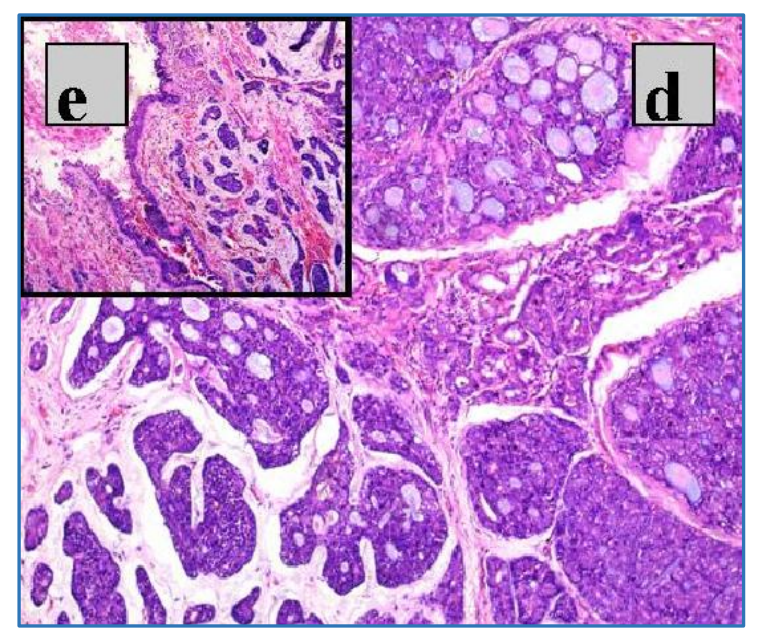

Figure 1d. Histopathology of Neoplasm shows Monomorphic Population of Cells in Cribriform Pattern with Central Homogeneous Eosinophilic Material (H and $E$ stain, $x$ 100). Figure 1e. Inset: Histopathology shows an Infiltrating Neoplasm in Subepithelial Region of Bronchus with Focal Ulceration (H and E stain, $x$ 100)

\section{DISCUSSION}

In this study, 12 cases were diagnosed as Small Cell Lung Carcinoma (SCLC) based on morphology of cells; 92\% ( $n=11)$ of the patients were males. Family history of colonic carcinoma was present in 1 case. Two patients had clinical evidence of Superior Vena Cava Obstruction (SVO). Radiologically, these tumours showed equal involvement of right and left lungs, centrally located in $75 \%$ of cases $(n=9)$ and in $25 \%$ of cases $(n=3)$ an extensive pattern. At the time of diagnosis metastasis was present in all patients (100\%), either local or distant. In accordance with the IASLC modified staging $75 \%(n=9)$ of patients had limited disease, while $25 \%$ $(n=3)$ of patients had extensive disease. One patient had leukoerythroblastic blood picture and vertebral bone metastasis; other sites of distant metastasis were liver (2 cases) and opposite lung (1 case). Biopsy was done in one case and histopathology confirmed the diagnosis.

In the current study, Squamous Cell Carcinoma (SCC) was diagnosed in 17 patients. A few pleomorphic cells and multinucleated tumour cells were observed in 4 and 2 cases respectively. Many pleomorphic cells and multinucleated tumour cells were observed in 1 case each. Macronucleolus and micronucleolus was evident in 1 and 3 cases respectively. All patients were males (100\%). Radiologically, tumour was in right lung in $64.7 \%(\mathrm{n}=11)$ of cases, majority had central $(53 \%, n=9)$ location followed by extensive $(35 \%, n=6)$ pattern. At the time of diagnosis all cases had evidence of metastasis (100\%), either local or distant and TNM stage was II in 4 cases, III in 11 cases, IV in 2 cases. Distant metastasis to opposite lung and bilateral adrenal gland was present in 1 case each. Malignant cells could be demonstrated in pleural fluid in 1 out of 5 cases with pleural effusion. Histopathological study was done in 7 cases, of which 5 cases correlated with cytological diagnosis and remaining 2 cases were diagnosed as poorly differentiated carcinoma.

A total of 40 cases were diagnosed as Adenocarcinoma (ADCA). A few pleomorphic cells and multinucleated tumour cells were observed in 15 and 7 cases respectively. Many pleomorphic cells and multinucleated tumour cells were observed in 2 cases each; 12 cases showed vacuolated cells. Macronucleolus and micronucleolus were observed in 23 and 2 cases respectively, while in 2 cases a mixed population of cells was seen; $97.5 \%(n=39)$ of the patients were males. One case had past history of interstitial lung disease. Family history of malignancy was present in 3 cases (Urothelial carcinoma, gastric carcinoma and pancreatic carcinoma). Clinical evidence of SVO was present in 1 patient. Radiologically, primary tumour was in right lung in $67.5 \%$ $(n=27)$ cases and $60 \%(n=24)$ had peripheral location. At the time of diagnosis, $85 \%(n=34)$ of cases had evidence of metastasis and TNM stage was I in 6 cases, II in 6 cases, III in 9 cases and IV in 19 cases. Common sites of distant metastasis were opposite lung ( 9 cases), bone ( 7 cases), adrenal gland ( 4 cases), liver (3 cases), brain (2 cases) and spleen (1). Malignant cells could be demonstrated in pleural fluid in 2 out of 9 cases with pleural effusion. Biopsy was done in 2 cases and histopathology confirmed the diagnosis.

Diagnosis of Adenoid Cystic Carcinoma (AdCC) was made in a 25-year-old male who presented with dyspnoea. Bronchoscopy and CT chest showed a primary tumour (T3) in right main bronchus with TNM stage I. He was treated with pneumonectomy and histopathology confirmed the cytological diagnosis. [Fig.1a-d]. 
In 29 cases, even though primary lung malignancy was diagnosed by radiological studies and adequate cellularity was present in cytology smears, a definite pattern or differentiation was not observed, hence were diagnosed as Non-Small Cell Carcinoma Not Otherwise Specified (NSCC NOS). Occasional pleomorphic cells and multinucleate tumour giant cells were observed in 5 and 2 cases respectively. Numerous discohesive multinucleate tumour giant cells and pleomorphic cells were observed in 5 cases and one of this showed emperipolesis, while 2 had vacuolated cytoplasm. Cells with micronucleolus were seen in 8 cases, macronucleolus in 2 cases and both type of cells in 2 cases; $89.6 \%(n=26)$ of the patients were males. Polyclonal gammopathy was detected in one among the 4 patients with a treatment history of pulmonary tuberculosis. Family history of lung cancer was present in 1 case. Evidence of Horner's syndrome was present in 1 case. Radiologically, in $72.4 \%$ $(n=21)$ of cases, primary tumour was in right lung and commonest location was central $(48.2 \%, n=14)$ followed by peripheral location $(34 \%, n=10)$. At the time of diagnosis, 93.1\% ( $n=27)$ of cases had evidence of metastasis and TNM stage was I in 2 cases, II in 7 cases, III in 7 cases and IV in 13 cases. Distant metastases were detected in opposite lung (6), bone (5), liver (3), adrenal (2), brain (1), skin (1), kidney (1) and spleen (1). Confirmation of malignancy was done in 8 patients by histopathology, 6 were diagnosed as poorly differentiated carcinoma and 2 were as squamous cell carcinoma.

Bronchoalveolar lavage from a 70-year-old male with a central lung mass showed a few discohesive malignant cells without any definite differentiation. It was diagnosed as smear positive for malignant cells. Subsequent biopsy from the same lesion was diagnosed as poorly differentiated carcinoma. At the time of diagnosis, he had pericardial effusion and T3 tumour in left lung with TNM stage III.

In the current study, the peak age group affected by lung carcinoma was $7^{\text {th }}$ decade which was consistent with the observations of Sundaram V et al[8] from Kolkata; however, in another study from Kerala[22] it was in $6^{\text {th }}$ decade. [Table 4] In Kerala incidence of lung carcinoma in females is comparatively less than that in other states. In this study, 9\% of cases had past history of pulmonary tuberculosis. Family history of cancer was present in $5 \%$ cases in the current study, while it was $21.7 \%$ in the study of Binukumar B et al.[22] Similar to the observations of Dhandapani $\mathrm{S}$ et al,[21] cough was the commonest symptom in patients with lung cancer but comparatively pleural effusion was present at the time of diagnosis in lesser number of patients (19\% vs $27.8 \%)$. Mild preponderance for right lung involvement was observed in this study, while not much difference was observed by Binukumar $B$ et al.[22] Radiologically, commonest location of lung carcinoma was hilar or perihilar (44\%). Similar to the findings in other studies, the commonest primary lung carcinoma was NSCC. Consistent with the observations of Sundaram $\mathrm{V}$ et al ${ }^{[8]}$ and Dhandapani $S$ et al,[21] adenocarcinoma was the most common NSCC observed in the current study. More than $60 \%$ lung cancer cases were detected before the stage IV in the current study, while Sundaram V et al ${ }^{[8]}$ reported that $60 \%$ of their cases were diagnosed with stage IV disease. Commonest sites of distant metastasis observed in our study were opposite lung (17), bone (14), liver (8), adrenal (8), brain (3), spleen (1) and kidney (1).

\section{Limitations of the Study}

Majority $(72 \%)$ of the cases in our study population were diagnosed with disease above TNM stage II, so biopsy of the tumour was carried out only in limited number of patients and correlation with histopathology was possible in only $20 \%$ of cases.

\section{CONCLUSION}

Lung carcinoma predominantly develops in elderly males and the majority of them have TNM stage above II disease at the time of diagnosis. In many situations cytology is the only diagnostic method available for guiding therapeutic decisions in the management of patients with lung cancer. Similar to the change in pattern of primary lung carcinoma in Western countries, adenocarcinoma of lung has surpassed squamous cell carcinoma here too.

\section{ACKNOWLEDGEMENT}

I would like to acknowledge Dr. Sankar S, Professor and HOD, Department of Pathology, for providing inspiration and guidance. I would also like to acknowledge all the clinicians of Department of Pulmonary Medicine in our Institution for providing adequate samples, and all staffs in the Laboratory who gave technical support for this study.

\section{REFERENCES}

[1] https://www.iarc.fr/en/mediacentre/pr/2013/pdfs/ pr223_E.pdf

[2] www.worldlifeexpectancy.com/usa-cancer-report

[3] http://seer.cancer.gov/statfacts/html/lungb.html 2016.

[4] Viswanathan R, Gupta S, Iyer PVK. Incidence of primary lung cancer in India. Thorax 1962;17(1):73-6.

[5] Sen U, Sankaranarayanan R, Mandal S, et al. Cancer patterns in eastern India: the first report of the Kolkata cancer registry. Int J Cancer 2002;100(1):8691.

[6] Hammar SP, Brambilla C, Pugatch B, et al. Squamous cell carcinoma. In: Travis WD, Brambilla E, MullerHermelink HK, et al. eds. World Health Organization classification of tumours. Pathology and genetics of tumours of the lung, pleura, thymus and heart. Lyon: IARC Press 2004:26-37.

[7] Osterlind K, Andersen PK. Prognostic factors in small cell lung cancer: multivariate model based on 778 patients treated with chemotherapy with or without irradiation. Cancer Res 1986;46(8):4189-94.

[8] Sundaram V, Sanyal N. Clinicopathological profile of bronchogenic carcinoma in a tertiary care hospital in eastern part of India. Clin Cancer Investig J 2014;3(3): 220-4.

[9] Roggli VL, Vollmer RT, Greenberg SD, et al. Lung cancer heterogeneity: a blinded and randomised study of 100 consecutive cases. Hum Pathol 1985;16(6): 569-79. 
[10] Travis WD, Brambilla E, Nicholson AG, et al. The 2015 World Health Organization classification of lung tumors. Impact of genetic, clinical and radiologic advances since the 2004 classification. J Thoracic Oncol 2015;10(9):1243-60.

[11] Melamed MR. Tumors of the lung: conventional cytology and aspiration biopsy. In: Koss LG, Melamed MR. eds. Koss diagnostic cytology and its histopathologic bases. $5^{\text {th }}$ edn. Philadelphia: Lippincott Williams and Wilkins 2006; p. 646.

[12] Bhatia A, Singh N, Arora VK. A perspective on cytology of lung cancer. Indian $\mathrm{J}$ Chest Dis Allied Sci 2004;46:81-3.

[13] Valaitis J, Warren S, Gamble D. Increasing incidence of adenocarcinoma of the lung. Cancer 1981;47(5):10426.

[14] Janssen-Heijnen ML, Coebergh JW. The changing epidemiology of lung cancer in Europe. Lung Cancer 2003;41(3):245-58.

[15] Vincent RG, Pickren JW, Lane WW, et al. The changing histopathology of lung cancer: a review of 1682 cases. Cancer 1977;39(4):1647-55.

[16] Behera D, Balamugesh T. Lung cancer in India. Indian J Chest Dis Allied Sci 2004;46(4):269-81.
[17] Singh N, Aggarwal AN, Gupta D, et al. Unchanging clinico-epidemiologcal profile of lung cancer in north India over three decades. Cancer Epidemiol 2010;34(1):101-4.

[18] Saha A, Kumar K, Choudhuri MK. Computed tomography- guided fine needle aspiration cytology thoracic mass lesions: a study of 57 cases. J Cytol 2009;26(2):55-9.

[19] Noronha V, Dikshit R, Raut N, et al. Epidemiology of lung cancer in India: focus on the differences between non-smokers and smokers: a single-centre experience. Indian J Cancer 2012;49(1):74-81.

[20] Malik PS, Sharma MC, Mohanti BK, et al. Clinicopathological profile of lung cancer at AIIMS: a changing paradigm in India. Asian Pac J Cancer Prev 2013;14(1):489-94.

[21] Dhandapani S, Srinivasan A, Rajagopalan R, et al. Clinicopathological profile of lung cancer patients in a teaching hospital in south India. J Cardio Thorac Med 2016;4(2):440-3.

[22] Bhaskarapillai B, Kumar SS, Balasubramanian S. Lung cancer in Malabar Cancer Center in Kerala - a descriptive analysis. Asian Pacific J Cancer Prev 2012;13(9):4639-43. 